\title{
Ileus Caused by Phytobezoar; Two Cases Two Approaches
}

\author{
Mehmet Buğra Bozan ${ }^{1 *}$, Fatih Erol ${ }^{1}$, Burhan Hakan Kanat ${ }^{1}$, Tamer Gündoğdu' ${ }^{1}$, Özkan Alataş ${ }^{2}$, Haşim Nar $^{3}$ and \\ Ayşe Azak Bozan ${ }^{4}$ \\ ${ }^{1}$ Department of General Surgery, Medical Sciences University, Turkey \\ ${ }^{2}$ Department of Radiology, Medical Sciences University, Turkey \\ ${ }^{3}$ Department of Gastroenterology, Medical Sciences University, Turkey \\ ${ }^{4}$ Department of Anesthesiology and Reanimation, Medical Sciences University, Turkey \\ Received: January 04, 2018; Published: March 05, 2018 \\ *Corresponding author: Mehmet Buğra Bozan, Department of General Surgery, Turkish Ministry of Health, Medical Sciences University, Elazig \\ Training and Research Hospital, Turkey, Tel: +90-0530-341 50 44; Email: bbozan@yahoo.com
}

\section{Abstract}

Bezoars are masses in the gastrointestinal tract caused by indigestable foods or other materials (like drugs, hair). Treatment can be done with medically, endoscopical approaches or surgical interventions (with milking or gastrotomy or enterotomi ile excision of fitobesoar or resection with anastomosis if intestinal ischemia occurs). We shared two patients with ileus due to Phytobesoar treated with surgical interventions.

Keywords: Ileus; Phytobezoar; Emergent surgery; Emergent endoscopic intervention

\section{Introduction}

Bezoars are massive formations caused by indigestible foods or other substances (such as medicine, hair) in the gastrointestinal tract. Various causes (stomach surgeries, eating habits such as little chewing, psychiatric problems, gastric motility disorders due to endocrinologic diseases such as diabetes mellitus) play a role in its occurrence $[1,2]$. We shared two cases treated in our clinic due to phytobezoar-related mechanical obstruction.

\section{Case 1}

A 75-year-old male patient presented with the complaints of abdominal pain, nausea and vomiting for two days was evaluated in the emergency department. Stool discharge was present. We learned from the history that he had undergone gastric surgery due to ulcer 25 years ago and coronary by-pass surgery 4 years ago. Physical examination revealed midline operation scar above the belly and epigastric distention and tenderness. No other pathologic finding was detected in other abdominal quadrants. The patient's leukocytosis value was $13000 / \mathrm{mm}^{3}$. No other pathological finding was found. No pathology was visualized in the standing direct abdominal x-ray. The urgent or emergent abdominal computed tomography revealed a phytobezoar-like appearance causing obstruction at the gastric outlet (Figure 1 \& 2).

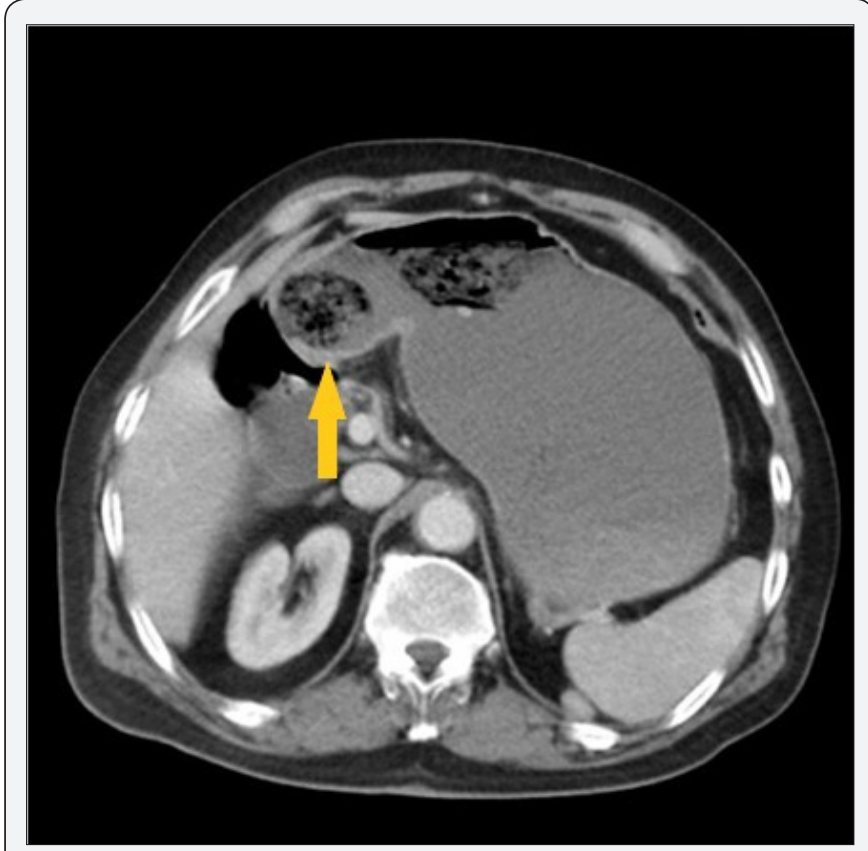

Figure 1: First patient's CT image before endoscopic evaluation (Dilatated stomach and phytobesoar in gastric antrum) (Phytobezoar was shown with yelow arrow). 


\section{Open Access Journal of Surgery}

In the urgent endoscopic examination of the patient, the stomach was visualized to be full, showing an obstruction along with phytobezoar at the outlet (Figure 3). The phytobezoar was broken down with endoscopic hook and its transition to the duodenum was visualized (Figure 4). However, as a result of distention finding in the patient whose vomiting complaint have restarted during the follow-up, abdominal CT was repeated and phytobezoar causing obstruction at the ileum was visualized (Figure $5 \& 6$ ). An emergent operation was planned for the patient, and prior to the operation, prophylactic $1 \mathrm{~g}$ of cephazolin and $500 \mathrm{mg}$ of metronidazole were intravenously administered and the patient was taken into emergent operation and underwent enterotomy after diagnostic laparotomy, and phytobezoar was removed (Figure $7 \& 8$ ). The patient who did not have any complaint or complication postoperatively, was discharged.

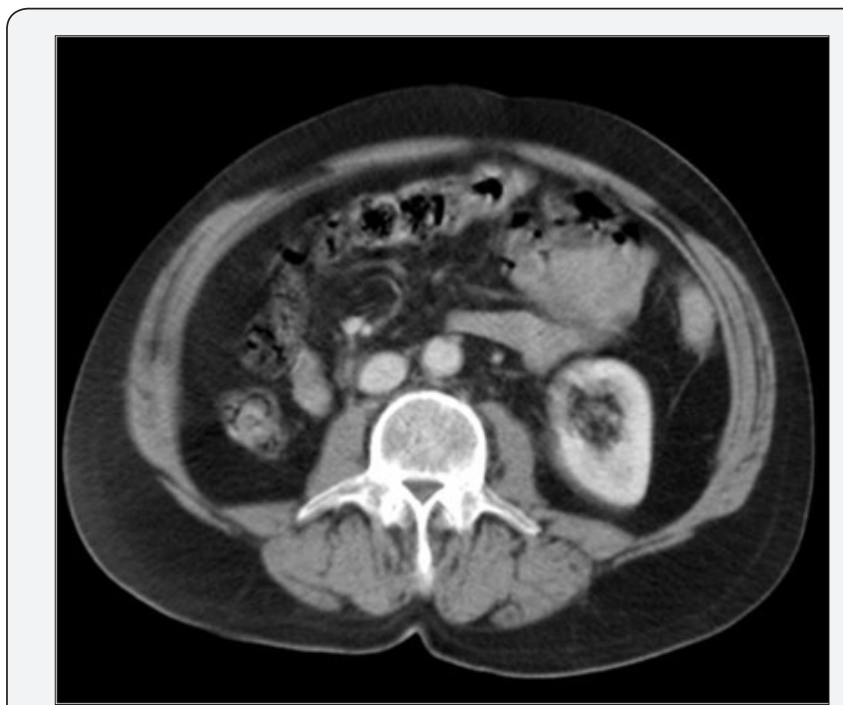

Figure 2: First patient's intestinal images in CT images before endoscopic intervention.

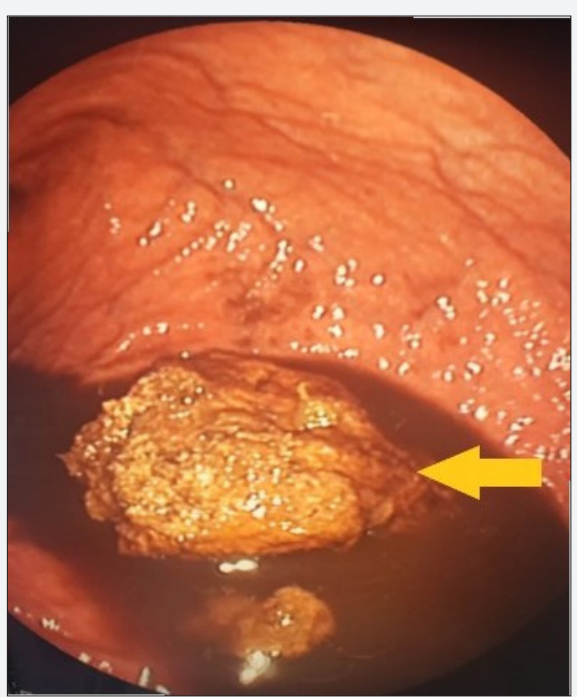

Figure 3: Phytobezoar in the gastric antrum shown with yellow arrow, Endoscopic view.

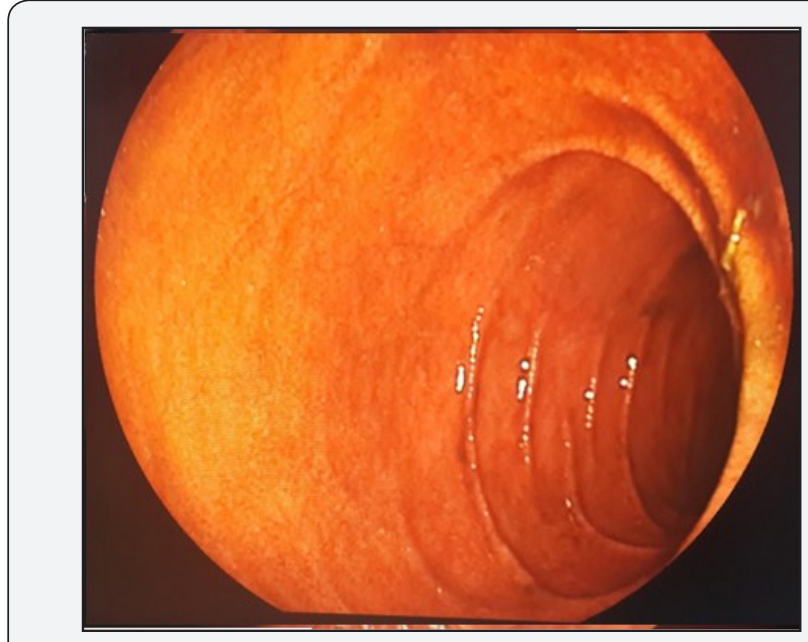

Figure 4: After endoscopic taking to pieces of phytobezoar, view of duodenum.

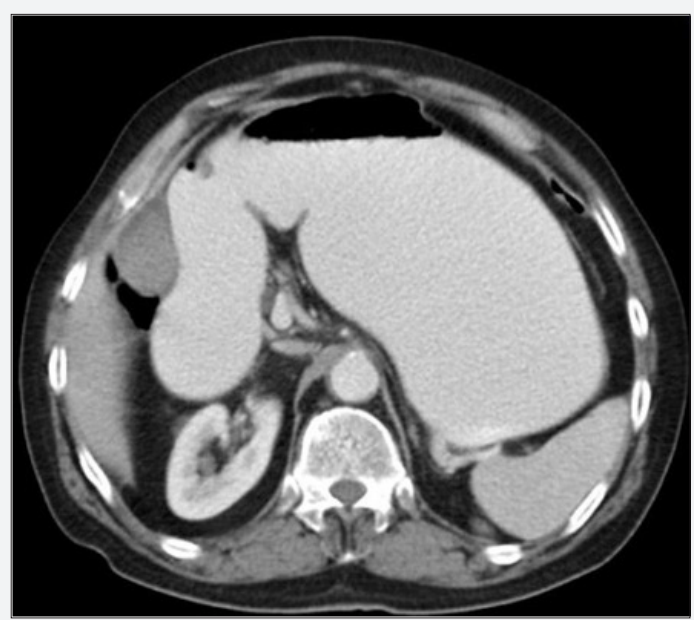

Figure 5: First patient's CT image after endoscopic intervention, dilatated stomach.

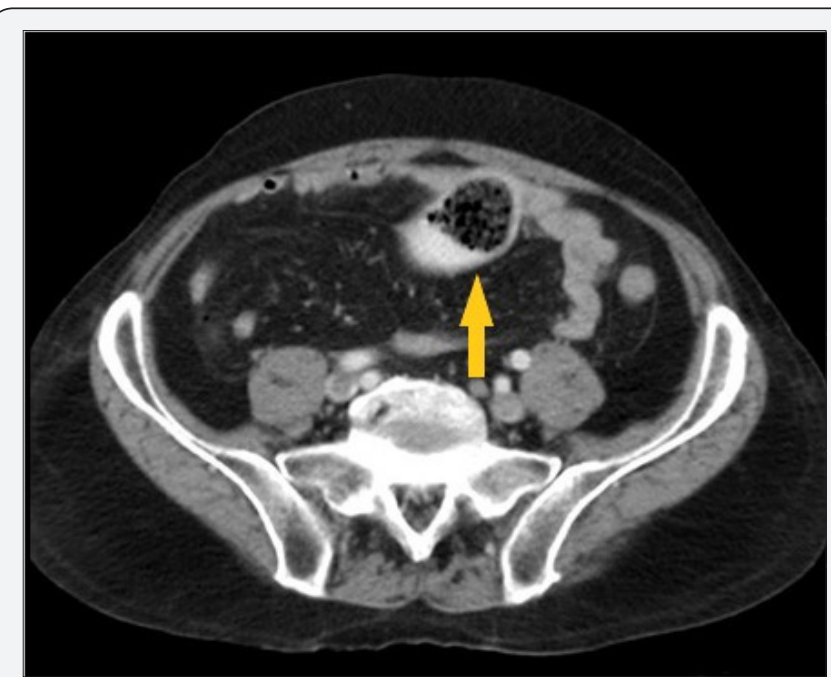

Figure 6: First patient's CT image after endoscopic intervention, migrated phytobezoar in intestine (Phytobezoar was shown with yellow arrow). 


\section{Open Access Journal of Surgery}

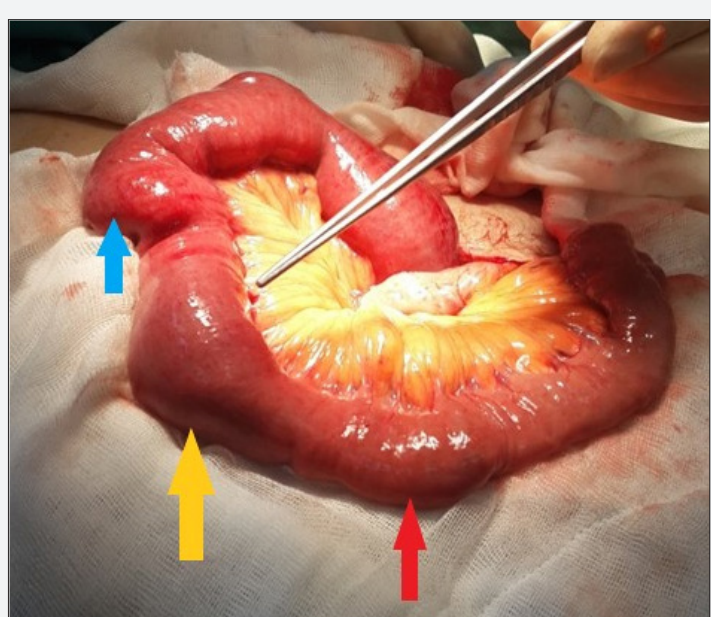

Figure 7: First patient's operative views; intestinal obstruction caused by phytobezoar (Dilatated proximal intestine shown with blue arrow, phytobezoar onstruction area shown with yellow arrow, distal intestine shown with red arrow).

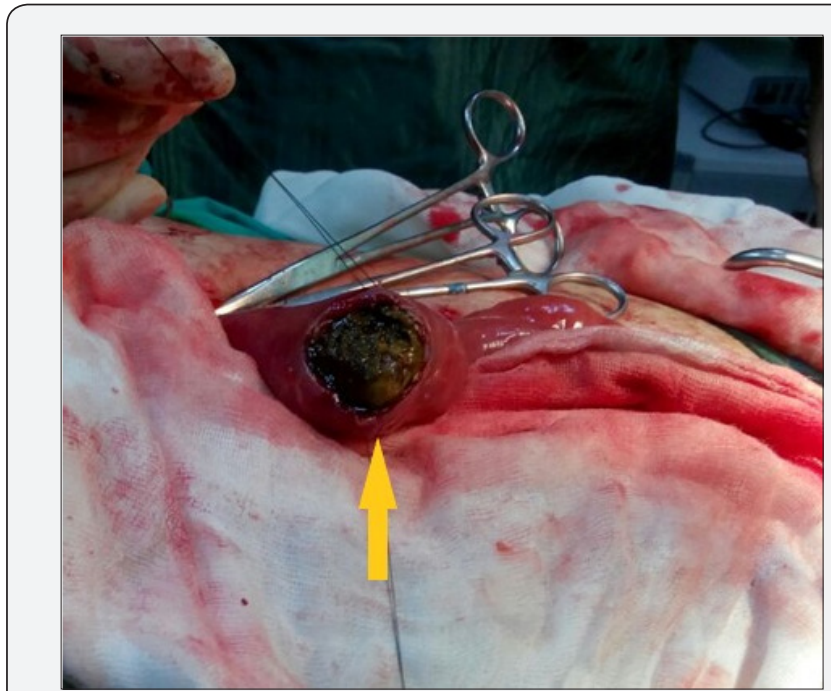

Figure 8: First patient's operative views; phytobezoar seen in intestine after enterostomy (Phytobezoar was shown with yellow arrow).

\section{Case 2}

A 35-year-old male patient presented with the complaints of severe abdominal pain, nausea and vomiting for approximately six hours was evaluated in the emergency department. We learned from the history that the patient, who did not have any concomitant disease or previous surgery, had eaten lots of fruits with solid consistency without chewing too much. The patient, who had diffuse abdominal distention on physical examination, had increased bowel sounds and diffuse abdominal tenderness. Laboratory results showed no other pathological finding other than leukocytosis $\left(12500 / \mathrm{mm}^{3}\right)$. The urgent abdominal CT of the patient performed for the purpose of determining the ileus etiology revealed a phytobezoar-related obstruction in the ileum and dilatation in the proximal loops (Figure 9).

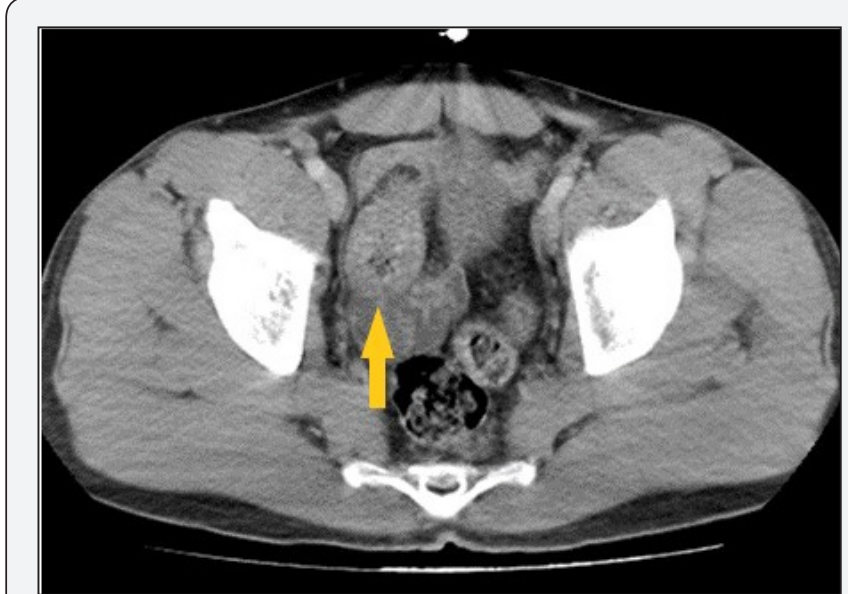

Figure 9: Second patient's CT image before surgical intervention (Phytobezoar was shown with yellow arrow).

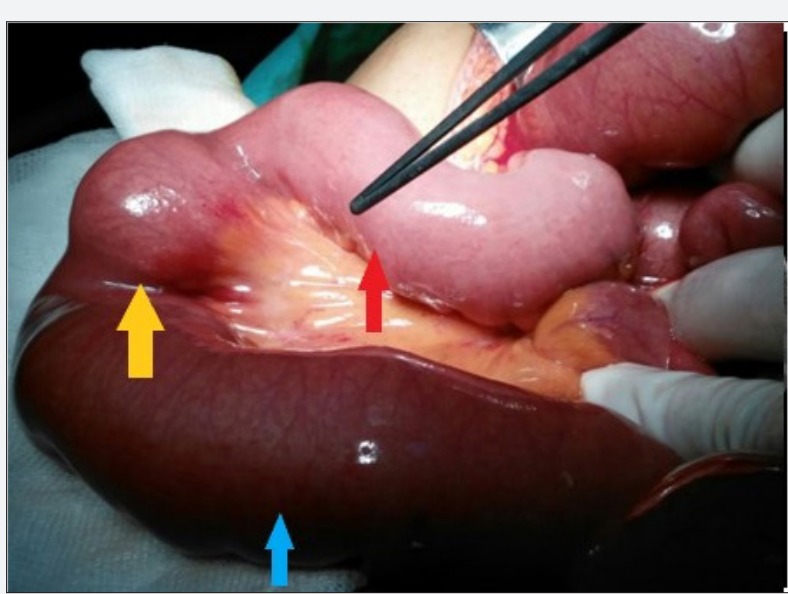

Figure 10 : Second patient's operative views; intestinal obstruction caused by phytobezoar (Dilatated proximal intestine shown with blue arrow, phytobezoar onstruction area shown with yellow arrow, distal intestine shown with red arrow).

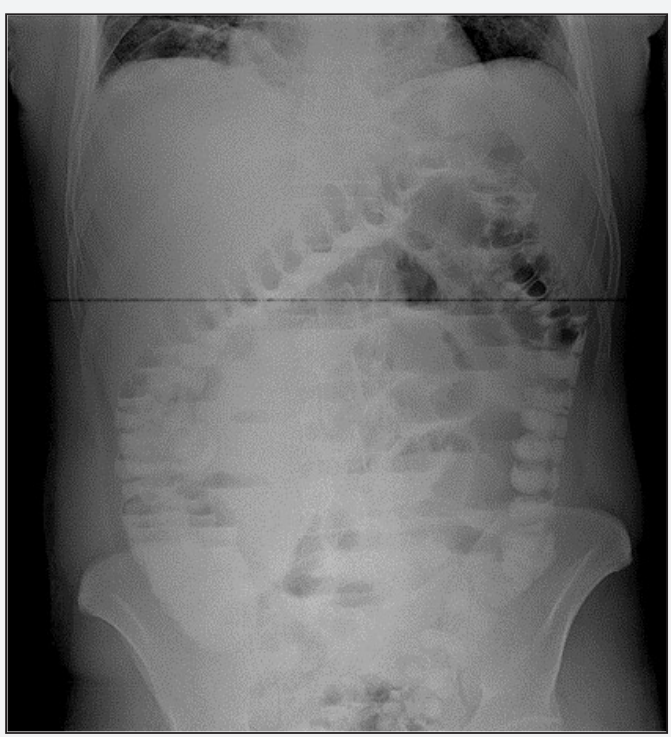

Figure 11: Second patient's plane graphy after surgery. 
Prior to the operation, $1 \mathrm{~g}$ of cephazolin and $500 \mathrm{mg}$ of metronidazole were prophylactically administered to the patient. After the diagnostic laparotomy of the patient, who was taken into emergent operation, it was observed that the ileal loops were dilated to the proximal due to phytobezoar, and that the phytobezoar showed an intraluminal mass appearance (Figure 10). The phytobezoar was then decompressed (milked) towards the colon and broken down. The patient, who did not have any complaint in the postoperative period, underwent contrast-enhanced abdominal x-ray for the purpose of passage evaluation, and it was visualized that the passage was obtained and the contrast substance passed through the colon (Figure 11). The patient, who did not have any complication, was discharged with recommendations.

\section{Discussion}

The massive structures caused by undigested food or waste, or by other substances in the gastrointestinal tract is called bezoar $[1,2]$. Depending on the factor involved, bezoars are named as phytobezoars (due to food residues), pharmacobezoars (due to drugs), trichobezoars (due to hair ingestion) and lectobezoars seen in neonates $[3,4]$. As in our cases, the majority of cases are due to phytobezoars, in other words, due to petrified foods. There are numerous underlying causes for the formation of bezoar. In cases where especially gastric acid release and motility are disrupted, as in our first case, previous gastric surgery (truncal vagotomy, billroth I-II, pyloroplasty, etc.) creates a susceptibility to the formation of bezoars [1,5]. Furthermore, psychiatric problems and eating habits like little chewing, as in our second case, also play a role in the formation of bezoars. Diseases that impair the gastric motility, such as diabetes mellitus, cause a susceptibility to the formation of bezoars $[1,6]$.

Clinically, patients present with obstruction findings, such as abdominal distention, abdominal pain, nausea and vomiting [1]. Direct $\mathrm{x}$-rays, the firstline diagnostic techniques, may provide visualization of ileus findings, such as air-fluid levelings, as well as free air in cases of perforation. However, they are not sufficient to reveal the etiologic cause [1]. The abdominal CT is an important diagnostic tool with a sensitivity rate of $90 \%$ and a specificity rate of $96 \%$. Well-demarcated intra-luminal mass with air bubbles, along with dilated intestinal loops and collapsed loops following mass can be visualized in CT [7]. In our first case, a gastric phytobezoar that migrated after the endoscopy was visualized in the jejunal loops in the tomographic images (Figures 1-4). Whereas in our second case, bezoar causing obstruction in the ileum was visualized (Figure 5).

In the case of gastric bezoars, endoscopy is both used as diagnostic and therapeutic tool. As in our first case, bezoars are expected to be both diagnosed and discharged in natural ways by breaking down with the help of endoscopy (Figure 3 $\& 4)$. However, patients should be closely followed up after the procedure since the bezoar fragments may sometimes re-join at the more distal parts and may cause obstruction, as in our first case $[1,8]$. The pharmacological treatment also has a place in the treatment before surgical procedures for the purpose of dissolving the bezoar with different substances depending on the location. Substances such as pineapple juice, acetyl cysteine, Coca Cola ${ }^{\circledR}$ have been used for this purpose. The endoscopic break down of bezoar enhances the efficacy of these substances $[9,10]$.

Surgical interventions can be performed with laparoscopy or laparotomy in cases of gastric bezoars that cannot be broken down or removed endoscopically and/or medically, or in cases of ileus due to intestinal bezoar to which the endoscope cannot reach. In surgery, if there is no impairment in the intestinal circulatory, bezoar can be removed by enterotomy or gastrotomy, as in our first case, intestinal decompression (milking) procedure can be performed for the purpose of pushing the bezoar to the colon, as in our second case. If there is an impairment in the intestinal circulatory, resection anastomosis procedures may be another option $[1,11]$.

\section{Conclusion}

Although rare, mechanical obstructions may show up due to bezoars. Besides more common obstruction causes (such as brid ileus), bezoars should also be considered in the presence of ileus, especially in patients with previous gastric surgery or with disorder in eating habit.

\section{References}

1. Çolakoğlu T, Ezer A, Belli S, Aytaç Ö, Parlakgümüş A, et al. (2010) Bezoarlara bağlı barsak tıkanıklıkları. Ulusal Cerrahi Dergisi 26(3): 157-160.

2. Robles R, Parrilla P, Escamilla C, Lujan JA, Torralba JA, (1994) Gastrointestinal bezoars. Br J Surg 81(7): 1000-1001.

3. Chintamani, Durkhure R, Singh JP, Singhal V (2003) Cotton Bezoar-a rare cause of intestinal obstruction: case report. BMC Surg 3: 5.

4. Acar T, Tuncal S, Aydın R (2003) An unusual cause of gastrointestinal obstruction: bezoar. N Z Med J 116(1173): U422.

5. Cifuentes Tebar J, Robles Campos R, Parrilla Paricio P, Lujan Mompean JA, Escamilla C, et al. (1992) Gastric surgery and bezoars. Dig Dis Sci 37(11): 1694-1696.

6. Rogers LF, Davis EK, Harle TS (1973) Phytobezoar formation and food boli following gastric surgery AJR 119: 280-290.

7. Delabrousse E, Brunelle S, Saguet O, Destrumelle N, Landecy G, et al. (2001) Small bowel obstruction secondary to phytobezoar CT Findings. Clin Imaging 25(1): 44-46.

8. Iwamuro M, Tanaka S, Shiode J, Imagawa A, Mizuno M, et al. (2014) Clinical Characteristics and Treatment Outcomes of Nineteen Japanese Patients with Gastrointestinal Bezoars. Intern Med 53(11): 1099-1105.

9. Ertuğrul G, Coşkun M, Sevinç M, Ertuğrul F, Toydemir T (2012) Treatment of gastric phytobezoars with Coca-Cola ${ }^{\circledR}$ given via oral route: a case report. International Journal of General Medicine 5: 157161.

10. Karabıçak İ, Yürüker S, Kesicioğlu T, Çınar H, Polat C, et al. (2011) Bezoarların medikal tedavisinde ananas suyu: 4 hasta ile klinik deneyimimiz. Journal of Experimental Clinical Medicine 28(2): 55-58.

11. Ersan Y, Yavuz N, Yüceyar S, Çiçek Y, Ergüney S, et al. (2005) Cerrahi Tedavi Gerektiren Mide Bezoarları. Cerrahpaşa J Med Cerrahpaşa Tıp Dergisi 36(3): 128-133. 
This work is licensed under Creative Commons Attribution 4.0 License

DOI: 10.19080/OAJS.2018.08.555741
Your next submission with Juniper Publishers will reach you the below assets

- Quality Editorial service

- Swift Peer Review

- Reprints availability

- E-prints Service

- Manuscript Podcast for convenient understanding

- Global attainment for your research

- Manuscript accessibility in different formats ( Pdf, E-pub, Full Text, Audio)

- Unceasing customer service

Track the below URL for one-step submission https://juniperpublishers.com/online-submission.php 